\title{
E-cigarettes versus NRT for smoking reduction or cessation in people with mental illness: secondary analysis of data from the ASCEND trial
}

\author{
Brigid O'Brien, Oliver Knight-West, Natalie Walker*, Varsha Parag and Christopher Bullen
}

\begin{abstract}
Background: People with mental illness have higher rates of smoking than the general population and are at greater risk of smoking-related death and disability. In smokers from the general population, electronic cigarettes (e-cigarettes) have been shown to have a similar effect on quit rates as nicotine replacement therapy, but little is known about their effect in smokers with mental illness.
\end{abstract}

Methods: Secondary analysis of data from the ASCEND trial involving 657 dependent adult smokers motivated to quit, randomised to $16 \mathrm{mg}$ nicotine e-cigarette, $21 \mathrm{mg}$ nicotine patch, or $0 \mathrm{mg}$ nicotine e-cigarette, with minimal behavioural support. Using self-reported medication use and the Anatomical Therapeutic Chemical Classification System, we identified 86 participants with mental illness and analysed their cessation and smoking reduction outcomes.

Results: For e-cigarettes alone, and all interventions pooled, there was no statistically significant difference in biochemically verified quit rates at six months between participants with and without mental illness, nor in smoking reduction, adverse events, treatment compliance, or acceptability. Rates of relapse to smoking were higher in participants with mental illness. Among this group, differences between treatments were not statistically significant for cessation (patch 14\% [5/35], $16 \mathrm{mg}$ e-cigarette 5\% [2/39], $0 \mathrm{mg}$ e-cigarette $0 \%$ [0/12], $\mathrm{p}=0.245$ ), adverse events or relapse rates. However, e-cigarette users had higher levels of smoking reduction, treatment compliance, and acceptability.

Conclusions: The use of e-cigarettes for quitting appears to be equally effective, safe, and acceptable for people with and without mental illness. For people with mental illness, e-cigarettes may be as effective and safe as patches, yet more acceptable, and associated with greater smoking reduction.

Trial registration: Australian New Zealand Clinical trials Registry, number: ACTRN126100000866000.

Keywords: Electronic cigarette/e-cigarette, Tobacco, Smoking cessation, Mental illness, Nicotine, Harm reduction

\section{Background}

People affected by mental illness suffer excess morbidity and mortality, with much of this disparity attributable to cigarette smoking [1,2]. Such people are more cigarette dependent, smoke more heavily [3,4], are less likely to quit $[4,5]$ and have a smoking prevalence several times higher than those without mental illness [6]. Because mental illness is common, affecting around a quarter of people in any year in developed countries [7-9], smoking in this population accounts for a large proportion of the smoking-related disease burden and associated economic

\footnotetext{
* Correspondence: n.walker@auckland.ac.nz

National Institute for Health Innovation, School of Population Health, The University of Auckland, Auckland, New Zealand
}

costs for health systems [10]. Reducing smoking rates in people with mental illness is a public health priority.

People with mental illness are motivated to quit smoking $[4,11]$, but comparatively few data exist on the efficacy of standard cessation interventions when used by this population because they are routinely excluded from clinical trials. The available evidence suggests bupropion is effective, but it is unclear for varenicline and mixed for nicotine replacement treatment (NRT) [2,12-17]. Despite a reduction in smoking prevalence across the general population of most developed countries, there has been little progress in boosting successful quit rates among smokers with mental illness [7,18,19]. An urgent need exists to increase the availability of cessation 
interventions that have appeal and address the high levels of cigarette addiction in this population [18].

Electronic cigarettes (e-cigarettes) are nicotine delivery devices that have promise for smoking cessation: two published randomised controlled trials (RCTs) involving first generation e-cigarettes with low nicotine delivery among general populations of smokers suggest modest effectiveness, similar to nicotine patches with minimal behavioural support [20,21]. A third trial involving 'second generation' e-cigarettes also supports these findings [22]. Little is known about e-cigarette use in people with mental illness. Only six studies have been reported to date: a small $(\mathrm{n}=14)$ uncontrolled pilot study in patients with schizophrenia [23], three case reports of patients $(\mathrm{n}=1-2)$ with affective or anxiety disorders [24-26], a US population-based survey $(\mathrm{n}=10,041)$ [27], and a recently published cohort study of 956 smokers with severe mental illness participating in a smoking cessation trial that did not involve e-cigarettes [28]. The latter study found that $11 \%$ of participants used an e-cigarette during the study, and concluded that e-cigarette use was not associated with changes in smoking behaviour. However, it is not possible to draw such firm conclusions from the data because people who 'used' an e-cigarette once and never again were not differentiated from those who used them frequently and for several months. The other studies suggested e-cigarettes have cessation and harm reduction potential for people with mental illness, including in those who were not motivated to quit, or who had previously tried to quit with NRT but failed. The latter finding raises the possibility that e-cigarettes might have an advantage over NRT through their ability, over and above nicotine delivery, to provide a coping mechanism for conditioned smoking cues by replacing some of the rituals associated with smoking gestures [23].

In order to investigate the above hypothesis we examined data from the largest randomised controlled trial of e-cigarettes to date, the ASCEND trial, focussing on participants who stated they were taking mental illnessrelated medications, and therefore likely to have a mental illness. We hypothesised that 1) nicotine patches and e-cigarettes, individually and collectively, are equally as effective, safe and acceptable for smoking cessation and reduction for people with or without mental illness, and that 2) e-cigarettes are more effective and acceptable than nicotine patches for smoking cessation and reduction in people with mental illness.

\section{Methods}

The ASCEND trial protocol and main findings have been described in detail elsewhere [21,29]. In brief, 657 dependent smokers aged $\geq 18$ years, who were motivated to quit, were recruited from the community in
Auckland, New Zealand (NZ), and randomised in a 4:4:1 ratio to $16 \mathrm{mg}$ nicotine e-cigarettes (ad libitum use), $21 \mathrm{mg}$ nicotine patches (one daily) or $0 \mathrm{mg}$ e-cigarettes (ad libitum use), from one week before until 12 weeks after the nominated quit day. Low intensity behavioural support was offered via voluntary telephone counselling. Smokers with poorly controlled psychiatric disorders or chemical dependency other than nicotine were excluded. The Northern X Regional Ethics Committee of New Zealand approved the study (Number NTX/10/11/111); the Standing Committee on Therapeutic Trials approved the nicotine electronic cigarettes for research. All study procedures were conducted in accordance with the Declaration of Helsinki.

Participants were assessed by telephone at baseline, quit date (one week post-baseline), one, three and six months post quit-date. Concomitant medication use was assessed at each time-point. The Anatomical Therapeutic Chemical (ATC) Classification System was used to identify participants taking medications related to mental illness [30]. This system classifies drugs into groups according to system on which they act and their therapeutic, pharmacological and chemical properties [30]. ATC codes indicating mental illness include: antidepressants, psychostimulants, antipsychotics, anxiolytics, hypnotics/sedatives and drugs for addictive disorders. Participants were divided into two major groups; 'mental illness participants' (those who reported use of $\geq 1$ of the medications associated with mental illness), and 'nonmental illness participants' (no reported use of any medications associated with mental illness).

Baseline measures comprised demographic and smoking-related variables, including nicotine dependence [31], the Glover-Nilsson smoking behavioural questionnaire [GN-SBQ] [32], motivation to quit measured on a scale of $1-5$ (where 1 is very low and 5 is very high), and stage of addiction measured using the autonomy over smoking scale (AUTOS) [33]. The primary outcome was continuous smoking abstinence six months after quit day, verified by an exhaled breath carbon monoxide measurement of $<10 \mathrm{ppm}$ using a Bedfont Micro Smokerlyzer. Secondary outcomes included rate of smoking relapse (date of return to regular daily smoking), reduction in cigarettes smoked per day (CPD) in those who did not quit, treatment compliance (continuing use of treatment at three months), adverse events and acceptability measures (i.e. recommendation of product to friend; stopping use of product due to dislike).

Analyses were performed using SAS version 9.3. All tests were two-tailed, with significance set at $5 \%$. Continuous outcomes were compared using t-tests, and binary outcomes were compared using chi-squared tests (or Fisher's Exact test if cell counts were $<5$ ). Primary outcome analyses were undertaken on an intention-to-treat 
basis whereby participants with missing smoking status were assumed to be smoking. The primary outcome was adjusted for mental illness status (as defined above) using logistic regression.

\section{Results}

Overall 86 (13\%) of the 657 participants reported using $\geq 1$ medication associated with mental illness and $571(87 \%)$ reported no such medication use. Of the 86 mental illness participants, 39 were allocated to $16 \mathrm{mg}$ e-cigarettes, 35 to nicotine patches and 12 to $0 \mathrm{mg}$ e-cigarettes. Three-quarters $(74 \%, 64 / 86)$ reported using antidepressants, $28 \%(24 / 86)$ antipsychotics, 14\% (12/86) hypnotics/sedatives, 9\% (8/86) anxiolytics, and $1 \%(3 / 86)$ addictive disorder medications.

Participants categorised as having a mental illness had a mean age of 44 years $(\mathrm{SD}=12)$, mean smoking initiation age of 15 years ( $\mathrm{SD}=4), 66 \%$ (57) were female, almost half $(44 \%, 38)$ had $<12$ years school education and half (43) had made a quit attempt in the previous year. At baseline, participants with and without mental illness were similar with respect to age, gender, education, previous quit attempts, behavioural dependence, motivation to quit and stage of addiction . Compared to participants without mental illness, those with mental illness were less likely to be Māori (indigenous New Zealanders) $(8 \%[7 / 86]$ vs $36 \%[206 / 571, \mathrm{p}<0.001)$ or live with other smokers $(40 \%$ [34/86] vs $54 \%$ [308/571], $\mathrm{p}=0.012)$, and more likely to be nicotine dependent (mean Fagerstrom score 6.3 versus 5.4, $\mathrm{p}<0.0001$; highly dependent Fagerstrom score $>5: 70 \%$ vs $52 \%, p=0.003$ ) and smoke more CPD (mean 19.4 vs 17.8 respectively, $\mathrm{p}=0.049$ ). Baseline characteristics of participants with mental illness by intervention are shown in Table 1.

\section{Comparison of outcomes for participants with and without mental illness}

The pooled results across the three interventions for participants with mental illness compared with those without mental illness are shown in Table 2. No significant difference between the two groups was noted, except for a higher relapse rate in mental illness participants. The primary outcome remained unchanged after adjusting for mental illness. Forty-four adverse events occurred amongst 35 mental illness participants compared with 248 events amongst 194 non-mental illness participants. A single psychiatric adverse event occurred in the mental illness group: a depressive episode that was not considered study-related. The only study-related adverse event in this group was a sore throat in a person allocated $16 \mathrm{mg}$ e-cigarettes.

Similar results were found when we analysed the data by treatment allocation (Table 2). For participants allocated to e-cigarettes there were no significant differences in primary or secondary outcomes between those with and without mental illness. The exception was smoking relapse which occurred at a higher rate in mental illness participants (Table 2). For participants allocated the nicotine patch no significant differences in outcomes were found between those with and without mental illness, with one exception: the six month quit rate was higher in participants with mental illness compared to those without mental illness $(14 \%$ [5/35] vs 5\% [12/260] respectively, $\mathrm{p}=0.038$ ).

\section{Comparison of interventions for mental illness participants}

There were no significant differences in quit rates or relapse rates for participants with mental illness randomised to each of the three interventions (Table 3). Adverse event counts relative to the number of participants were similar (these were not subject to statistical testing due to small numbers). No serious study-related adverse events were noted in any group. For smoking reduction, compliance, and acceptability $16 \mathrm{mg}$ e-cigarettes outperformed nicotine patches. No significant difference was detected between $16 \mathrm{mg}$ and $0 \mathrm{mg}$ e-cigarettes for any outcome tested. Among mental illness participants allocated $16 \mathrm{mg}$ e-cigarettes, approximately half (53\%) liked their tactile, cigarette-like qualities, sensory familiarity, perceived health benefits, taste and ease of use.

Table 1 Baseline characteristics of mental illness participants by intervention

\begin{tabular}{llll}
\hline Characteristic & $\mathbf{2 1} \mathbf{~ m g}$ nicotine patch $\mathbf{( n = 3 5 )}$ & $\mathbf{1 6} \mathbf{~ m g}$ e-cigarette $\mathbf{( n = 3 9 )}$ & $\mathbf{0} \mathbf{~ m g ~ e - c i g a r e t t e ~} \mathbf{( n = 1 2 )}$ \\
\hline Mean age & $41(11)$ & $46(11)$ & $46(14)$ \\
Female gender & $69 \%(24)$ & $67 \%(26)$ & $59 \%(7)$ \\
Mean Fagerstrom score & $6.5(2.0)$ & $6.6(1.7)$ & $5.1(2.4)$ \\
Reported antidepressant use & $69 \%(24)$ & $77 \%(30)$ & $83 \%(10)$ \\
Reported antipsychotic use & $29 \%(10)$ & $23 \%(9)$ & $42 \%(5)$ \\
Reported anxiolytic use & $6 \%(2)$ & $13 \%(5)$ & $8 \%(1)$ \\
Reported hypnosedative use & $9 \%(3)$ & $15 \%(6)$ & $25 \%(3)$ \\
Reported drugs for addictive disorders use & $3 \%(1)$ & $3 \%(1)$ & $8 \%(1)$ \\
\hline
\end{tabular}

Data are mean (SD) or \% (n). 
Table 2 Comparison of outcomes for participants with and without mental illness displaying both pooled and intervention level results for the three interventions ( $21 \mathrm{mg}$ nicotine patch, $16 \mathrm{mg}$ e-cigarette, $0 \mathrm{mg}$ e-cigarette)

\begin{tabular}{|c|c|c|c|c|}
\hline Outcome & Intervention & $\begin{array}{l}\text { Mental Illness }(n=86,13 \%) \\
\text { patch } n=35,16 \text { mg e-cigarette } \\
n=39,0 \text { mg e-cigarette } n=12\end{array}$ & $\begin{array}{l}\text { No Mental Illness ( } n=571,87 \%) \\
\text { patch } n=260,16 \text { mg e-cigarette } \\
n=250,0 \text { mg e-cigarette } n=61\end{array}$ & $\begin{array}{l}\text { Difference } \\
\text { ( } p \text { value) }\end{array}$ \\
\hline \multirow{4}{*}{$\begin{array}{l}\text { Biochemically verified continuous } \\
\text { abstinence at six months } \%(n)\end{array}$} & All interventions pooled & $8 \%(7)$ & $6 \%(34)$ & 0.435 \\
\hline & $21 \mathrm{mg}$ nicotine patch & $14 \%(5)$ & $5 \%(12)$ & $0.038^{\mathrm{a}}$ \\
\hline & 16 mg e-cigarette & $5 \%(2)$ & $7 \%(19)$ & $0.750^{a}$ \\
\hline & 0 mg e-cigarette & $0 \%(0)$ & $5 \%(3)$ & - \\
\hline \multirow[t]{4}{*}{ Relapse rate at six months \% (n) } & All interventions pooled & $79 \%(68)$ & $67 \%(380)$ & 0.020 \\
\hline & $21 \mathrm{mg}$ nicotine patch & $71 \%(25)$ & $67 \%(175)$ & 0.931 \\
\hline & 16 mg e-cigarette & $85 \%(33)$ & $66 \%(164)$ & $<0.0001$ \\
\hline & 0 mg e-cigarette & $83 \%(10)$ & $67 \%(41)$ & 0.239 \\
\hline \multirow{4}{*}{$\begin{array}{l}\text { Mean reduction in CPD from } \\
\text { baseline to six months in those } \\
\text { that did not quit Mean (SD) }\end{array}$} & All interventions pooled & $7.7(6.7)$ & $8.4(7)$ & 0.508 \\
\hline & 21 mg nicotine patch & $5.7(6.3)$ & $7.4(7)$ & 0.299 \\
\hline & 16 mg e-cigarette & $9.9(7)$ & $9.4(7.1)$ & 0.743 \\
\hline & 0 mg e-cigarette & $4.7(3.5)$ & $8.3(5.9)$ & $0.129^{b}$ \\
\hline \multirow{4}{*}{$\begin{array}{l}\text { Percentage reduction in CPD from } \\
\text { baseline to six months in those } \\
\text { that did not quit Mean (SD) }\end{array}$} & All interventions pooled & $40 \%(30 \%)$ & $46 \%(33 \%)$ & 0.154 \\
\hline & 21 mg nicotine patch & $29 \%(30 \%)$ & $41 \%(35 \%)$ & 0.147 \\
\hline & 16 mg e-cigarette & $49 \%(28 \%)$ & $51 \%(31 \%)$ & 0.660 \\
\hline & 0 mg e-cigarette & $31 \%(26 \%)$ & $47 \%(28 \%)$ & $0.245^{b}$ \\
\hline \multirow{4}{*}{$\begin{array}{l}\text { Treatment compliance at three } \\
\text { months \% (n) }\end{array}$} & All interventions pooled & $39 \%(30)$ & $37 \%(167)$ & 0.757 \\
\hline & $21 \mathrm{mg}$ nicotine patch & $20 \%(6)$ & $18 \%(34)$ & 0.752 \\
\hline & 16 mg e-cigarette & $53 \%(19)$ & $51 \%(107)$ & 0.861 \\
\hline & 0 mg e-cigarette & $46 \%(5)$ & $54 \%(26)$ & 0.741 \\
\hline \multirow[t]{2}{*}{$\begin{array}{l}\text { Adverse events rate } \\
\text { (events/person month) }\end{array}$} & All interventions pooled & 0.078 & 0.084 & $\begin{array}{l}0.666 \text { (IRR 0.93, } \\
95 \% \text { Cl 0.68-1.28) }\end{array}$ \\
\hline & $\begin{array}{l}16 \mathrm{mg} \text { e-cigarette } \\
\text { and } 0 \mathrm{mg} \text { e-cigarette } \\
\text { combined }\end{array}$ & 0.05 & 0.05 & $\begin{array}{l}0.592 \text { (IRR 0.89, } \\
95 \% \text { Cl 0.59-1.35) }\end{array}$ \\
\hline \multicolumn{5}{|l|}{$\begin{array}{l}\text { Acceptability of intervention at } \\
\text { six months }\end{array}$} \\
\hline \multirow[t]{4}{*}{ Would recommend to a friend' $\%$ (n) } & All interventions pooled & $65 \%(49)$ & $72 \%(313)$ & 0.207 \\
\hline & $21 \mathrm{mg}$ nicotine patch & $37 \%(11)$ & $63 \%(19)$ & 0.122 \\
\hline & 16 mg e-cigarette & $83 \%(30)$ & $85 \%(175)$ & 0.752 \\
\hline & 0 mg e-cigarette & $80 \%(8)$ & $89 \%(42)$ & $0.594^{a}$ \\
\hline \multirow[t]{4}{*}{ 'Stopped as didn't like it '\% (n) } & All interventions pooled & $34 \%(21 / 62)$ & $32 \%(108 / 343)$ & 0.711 \\
\hline & $21 \mathrm{mg}$ nicotine patch & $41 \%(12 / 29)$ & $41 \%(169 / 169)$ & 0.956 \\
\hline & 16 mg e-cigarette & $29 \%(7 / 24)$ & $23 \%(33 / 146)$ & 0.482 \\
\hline & 0 mg e-cigarette & $22 \%(2 / 9)$ & $21 \%(6 / 28)$ & $1.000^{\mathrm{a}}$ \\
\hline
\end{tabular}

$\mathrm{CPD}=$ cigarettes per day smoked, $\mathrm{SD}=$ standard deviation, $\mathrm{IRR}=$ Incidence rate ratio, $\mathrm{Cl}=$ confidence interval, ${ }^{\mathrm{a}}$ Fishers Exact test, ${ }^{\mathrm{b}}$ Mann-Whitney test.

\section{Discussion}

Our findings suggest e-cigarettes could be a useful option for smoking cessation or harm reduction in smokers with mental illness. Our finding that e-cigarettes may be as effective, safe and acceptable for smoking cessation and reduction in people with mental illness as in those without is consistent with literature on standard cessation treatments in mental illness populations [2]. These findings, when considered with the results of the main ASCEND trial (which demonstrated non-inferiority of e-cigarettes to NRT in a general population), also suggest a possible role for e-cigarettes in smokers with mental illness.

The absolute effectiveness of both NRT and e-cigarettes was low for smokers with or without mental illness. More intensive behavioural support would likely have improved 
Table 3 Comparison of outcomes for mental illness participants who used $16 \mathbf{~ m g ~ n i c o t i n e ~ e - c i g a r e t t e s , ~} 0$ mg e-cigarettes and $21 \mathrm{mg}$ nicotine patches

\begin{tabular}{|c|c|c|c|c|}
\hline Outcome & $\begin{array}{l}21 \text { mg nicotine patch } \\
(n=35,40 \%)\end{array}$ & $\begin{array}{l}16 \text { mg nicotine e-cigarette } \\
(\mathrm{n}=39,45 \%)\end{array}$ & $\begin{array}{l}0 \text { mg nicotine e-cigarette } \\
(\mathrm{n}=12,14 \%)\end{array}$ & Difference (p-value) \\
\hline \multirow{3}{*}{$\begin{array}{l}\text { Biochemically verified continuous } \\
\text { abstinence at six months } \%(n)\end{array}$} & \multirow[t]{3}{*}{$14 \%(5)$} & \multirow[t]{3}{*}{$5 \%(2)$} & \multirow[t]{3}{*}{0} & 0.245 (patch vs. 16 mg e-cig) $^{a}$ \\
\hline & & & & - (16 mg vs. 0 mg e-cig) \\
\hline & & & & 0.115 (patch vs. combined e-cig) $)^{a}$ \\
\hline \multirow[t]{3}{*}{ Relapse rate at six months $\%(n)$} & \multirow[t]{3}{*}{$71 \%(25)$} & \multirow[t]{3}{*}{$85 \%(33)$} & \multirow[t]{3}{*}{$83 \%(10)$} & 0.169 (patch vs. 16 mg e-cig) \\
\hline & & & & 1.000 (16 mg vs. 0 mg e-cig) \\
\hline & & & & 0.149 (patch vs. combined e-cig) \\
\hline \multirow{3}{*}{$\begin{array}{l}\text { Mean reduction in CPD from } \\
\text { baseline to six months in those } \\
\text { that did not quit Mean (SD) }\end{array}$} & \multirow[t]{3}{*}{$5.7(6.3)$} & \multirow[t]{3}{*}{$9.9(7)$} & \multirow[t]{3}{*}{$4.7(3.5)$} & 0.035 (patch vs. 16 mg e-cig) \\
\hline & & & & 0.068 (16 mg vs. 0 mg e-cig) \\
\hline & & & & 0.083 (patch vs. combined e-cig \\
\hline \multirow{3}{*}{$\begin{array}{l}\text { Percentage reduction in CPD } \\
\text { from baseline to six months in } \\
\text { those that did not quit Mean (SD) }\end{array}$} & \multirow[t]{3}{*}{$29 \%(30 \%)$} & \multirow[t]{3}{*}{$49 \%(30 \%)$} & \multirow[t]{3}{*}{$31 \%(30 \%)$} & 0.025 (patch vs. 16 mg e-cig) \\
\hline & & & & 0.153 (16 mg vs. 0 mg e-cig) \\
\hline & & & & 0.049 (patch vs. combined e-cig) \\
\hline \multirow{3}{*}{$\begin{array}{l}\text { Treatment compliance at } \\
\text { three months } \%(n)\end{array}$} & \multirow[t]{3}{*}{$20 \%(6)$} & \multirow[t]{3}{*}{$53 \%(19)$} & \multirow[t]{3}{*}{$46 \%(5)$} & 0.006 (patch vs. 16 mg e-cig) \\
\hline & & & & 0.670 (16 mg vs. 0 mg e-cig) \\
\hline & & & & 0.006 (patch vs. combined e-cig) \\
\hline Adverse events & 17 (in 16 people) & 22 (in 15 people) & 5 (in 4 people) & - \\
\hline \multicolumn{5}{|l|}{$\begin{array}{l}\text { Acceptability of intervention at } \\
\text { six months }\end{array}$} \\
\hline \multirow[t]{3}{*}{ Would recommend to a friend' $\%$ (n) } & \multirow[t]{3}{*}{$37 \%(11)$} & \multirow[t]{3}{*}{$83 \%(30)$} & \multirow[t]{3}{*}{$80 \%(8)$} & $<0.001$ (patch vs. 16 mg e-cig) \\
\hline & & & & $1.000 \mathrm{a}$ (16 mg vs. 0 mg e-cig) \\
\hline & & & & $<0.001$ (patch vs. combined e-cig) \\
\hline \multirow[t]{3}{*}{ 'Stopped as didn't like it' \% (n) } & \multirow[t]{3}{*}{$41 \%(12 / 29)$} & \multirow[t]{3}{*}{$29 \%(7 / 24)$} & \multirow[t]{3}{*}{$22 \%(2 / 9)$} & 0.356 (patch vs. 16 mg e-cig) \\
\hline & & & & $1.000 \mathrm{a}$ (16 mg vs. 0 mg e-cig) \\
\hline & & & & 0.242 (patch vs. combined e-cig) \\
\hline
\end{tabular}

$\mathrm{CPD}=$ cigarettes per day smoked, $\mathrm{SD}=$ standard deviation, ${ }^{\mathrm{a}}$ Fishers Exact test.

the efficacy of all treatment arms across the entire sample, and is an especially important component of treatment for smokers with mental illness [34]. The extent of smoking reduction among participants without mental illness did not differ between treatments. However, at six months smokers with mental illness who had been allocated a nicotine e-cigarette smoked significantly fewer cigarettes than those allocated to patch or $0 \mathrm{mg}$ e-cigarette. This potential for harm reduction in this population warrants further exploration, and aligns with research recommendations from the UK's National Institute for Health and Clinical Excellence [35].

Among people with mental illness, e-cigarettes appeared to have a similar safety profile to nicotine patch, yet were generally more acceptable and associated with greater compliance. These findings align with the general population outcomes of the main trial. Many of the observed advantages of e-cigarettes over patch were evident irrespective of whether nicotine was present, suggesting that some of the benefit conferred is due to the tactile properties of the e-cigarette simulating the behavioural and sensory aspects of smoking. The absence of any difference between patch and e-cigarettes for quit rates and relapse rates is difficult to interpret given the small numbers. The reason for the higher quit rate observed for patch users with mental illness compared to those without is unknown, but may be a chance finding.

Limitations of the trial have been discussed in the original publication [21], including issues associated with the e-cigarettes used in the trial (e.g. variable nicotine content and delivery, and battery failure). Further limitations specific to these analyses should also be acknowledged, and indicate findings need to be interpreted with caution and considered exploratory. First, the analyses presented were of secondary data and post-hoc, and multiple tests were undertaken thereby increasing the chances of a type 1 error. Second, the analyses involved a small sample size and therefore there was limited power to detect subgroup differences. Finally, the generalisability of the findings to the population of people with mental 
illness is limited by our use of a proxy measure for a diagnosis of mental illness and the exclusion of people with uncontrolled psychiatric or current chemical dependence from the trial. It is possible that medication use was under-reported, some mental illnesses may have been undiagnosed and therefore unmedicated, and some medications associated with mental illness could have been prescribed instead for pain or sleep disorders. On balance we believe our sample probably best represents those with moderate mental illness, while excluding those with very severe or milder (unmedicated) mental illness. It is also possible that a small proportion taking medication for pain or sleep disorders were wrongly classified as having mental illness. In our study population 13\% reported using one or more mental health medications, whereas in a survey of 2,299 NZ smokers between 2007-09 20\% had ever had a mental illness diagnosis and $10 \%$ had a high probability of a depressive or anxiety disorder [36]. Notwithstanding the prevalence of mental illness is likely to be higher in more dependent smokers than the general population of smokers, our findings align with population estimates.

\section{Conclusions}

Our findings suggest e-cigarettes are similarly effective, safe, and acceptable for smoking cessation and reduction in people with mental illness as those without; furthermore among people with mental illness they appear to be favoured over nicotine patches while yielding a greater decrease in cigarette consumption. To improve health outcomes in this priority group, new approaches to cessation support and harm reduction are urgently needed; our study suggests e-cigarettes warrant further investigation in this regard.

\section{Abbreviations \\ ATC: Anatomical Therapeutic Chemical; AUTOS: Autonomy over smoking scale; E-cigarettes: Electronic cigarettes; GN-SBQ: Glover-Nilsson smoking behavioural questionnaire; NRT: Nicotine replacement therapy; NZ: New Zealand; RCT: Randomised controlled trial.}

\section{Competing interests}

Funding for this study was provided by the Health Research Council of NZ Grant (10-243); the Health Research Council had no further role in study design; in the collection, analysis and interpretation of data; in the writing of the report; or in the decision to submit the paper for publication. We declare that we have received no support from any companies for the submitted work and have no non-financial interests that might be relevant to the submitted work. Chris Bullen has undertaken research on Ruyan e-cigarettes funded by Health NZ, independently of Ruyan. Natalie Walker has provided consultancy to the manufacturers of smoking cessation drugs, received honoraria for speaking at a research meeting and received benefits in kind and travel support from a manufacturer of smoking cessation drugs.

\section{Authors' contributions}

$\mathrm{CB}$ and NW were PI and a co-investigator respectively on the ASCEND trial. BO and OK-W designed this secondary analysis study. VP undertook the statistical analyses for the original trial and the secondary analysis. This article was written by $\mathrm{BO}$ with input from all co-authors. All authors contributed to and have approved the final manuscript.

\section{Acknowledgements}

The e-cigarettes and cartridges used in the ASCEND trial were Elusion brand products provided by PGM International, NZ. PGM International had no role in the study design, data collection, data analysis, data interpretation, or writing of this report. We thank the participants, co-investigators on the original ASCEND trial (C Howe, M Laugesen, H McRobbie, J Williman), research assistants, our colleagues, the Health Research Council of NZ, PGM International, and NZ Quitline. Natalie Walker is supported by a Heart Foundation Douglas Senior Fellowship in Heart Health (Prevention).

Received: 22 September 2014 Accepted: 4 March 2015

Published online: 24 March 2015

\section{References}

1. Brown S, Inskip H, Barraclough B. Causes of the excess mortality of schizophrenia. Br J Psychiatry. 2000;177:212-7.

2. Banham L, Gilbody S. Smoking cessation in severe mental illness: what works? Addiction. 2010;105(7):1176-89.

3. Campion J, Checinski K, Nurse J, McNeill A. Smoking by people with mental illness and benefits of smoke-free mental health services. Adv Psychiatr Treat. 2008;14:217-28.

4. Smith PH, Homish GG, Giovino GA, Kozlowski LT. Cigarette smoking and mental illness: a study of nicotine withdrawal. Am J Public Health. 2014;104(2):e127-33. doi:10.2105/ajph.2013.301502.

5. Smith PH, Mazure CM, McKee SA. Smoking and mental illness in the US population. Tob Control. 2014;23(e2):e147-53. doi:10.1136/ tobaccocontrol-2013-051466.

6. Callaghan RC, Veldhuizen S, Jeysingh T, Orlan C, Graham C, Kakouris G, et al. Patterns of tobacco-related mortality among individuals diagnosed with schizophrenia, bipolar disorder, or depression. J Psychiatr Res. 2014;48(1):102-10.

7. Centers for Disease Control and Prevention. Vital signs: Current cigarette smoking among adults aged aged $\geq 18$ Years-United States, 2009-2011. MMWR Morb Mortal Wkly Rep. 2013;62(5):81-7.

8. Wittchen HU, Jacobi F. Size and burden of mental disorders in Europe-a critical review and appraisal of 27 studies. Eur Neuropsychopharmacol. 2005;15:357-76.

9. McManus S, Meltzer H, Brugha T, Bebbington P, Jenkins R. Adult Psychiatric Morbidity Survey 2007. Results of a household survey. The NHS Health \& Social Care Information Centre, Social Care Statistics; 2009. http://www.hscic. gov.uk/catalogue/PUB02931/adul-psyc-morb-res-hou-sur-eng-2007-rep.pdf

10. McCreadie R, Kelly C. Patients with schizophrenia who smoke. Private disaster, public resource. Br J Psychiatry. 2000;176:109.

11. Siru R, Hulse GK, Tait RJ. Assessing motivation to quit smoking in people with mental illness: a review. Addiction. 2009;104(5):719-33.

12. Tsoi DT, Porwal M, Webster AC. Interventions for smoking cessation and reduction in individuals with schizophrenia. Cochrane Database Syst Rev. 2013;2:CD007253. doi:10.1002/14651858.CD007253.pub3.

13. Pachas G, Cather C, Pratt S, Hoeppner B, Nino J, Carlini S, et al. Varenicline for smoking cessation in schizophrenia: safety and effectiveness in a 12-week, open-label trial. J Dual Diagn. 2012;8(2):1178-125.

14. Rüther T, Bobes J, De Hert M, Svensson TH, Mann K, Batra A, et al. EPA Guidance on tobacco dependence and strategies for smoking cessation in people with mental illness. Eur Psychiatry. 2014;29(2):65-82. http://dx.doi. org/10.1016/j.eurpsy.2013.11.002.

15. van der Meer RM, Willemsen MC, Smit F, Cuijpers P. Smoking cessation interventions for smokers with current or past depression. Cochrane Database Syst Rev. 2013;8:CD006102. doi:10.1002/14651858.CD006102.pub2.

16. Kishi $\mathrm{T}$, Iwata N. Varenicline for smoking cessation in people with schizophrenia: systematic review and meta-analysis. Eur Arch Psychiatry Clin Neurosci. 2014. doi:10.1007/s00406-014-0551-3

17. Parker C, McNeill A, Ratschen E. Tailored tobacco dependence support for mental health patients: a model for inpatient and community services. Addiction. 2012;107 Suppl 2:18-25.

18. Royal College of Physicians. Smoking and Mental Health. London: RCP; 2013.

19. Cook BL, Wayne GF, Kafali EN, Liu Z, Shu C, Flores M. Trends in smoking among adults with mental illness and association between mental health treatment and smoking cessation. JAMA. 2014;311(2):172-82. doi:10.1001/ jama.2013.284985.

20. Caponnetto P, Campagna D, Cibella F, Morjaria J, Caruso M, Russo C, et al. Efficiency and Safety of an electronic cigarette (ECLAT) as tobacco cigarettes 
substitute: a prospective 12-month randomized control design study. PLoS One. 2013;8(6):e66317. doi:10.1371/journal.pone.0066317.

21. Bullen C, Howe C, Laugesen M, McRobbie H, Parag V, Williman J, et al. Electronic cigarettes for smoking cessation: a randomised controlled trial. Lancet. 2013;382(9905):1629-37. http://dx.doi.org/10.1016/501406736(13)61842-5.

22. Adriaens K, Van Gucht D, Declerck P, Baeyens F. Effectiveness of the electronic cigarette: an eight-week flemish study with six-month follow-up on smoking reduction, craving and experienced benefits and complaints. Int J Environ Res Public Health. 2014;11(11):11220-48. doi:10.3390/ ijerph111111220.23.

23. Caponnetto P, Auditore R, Russo C, Cappello GC, Polosa R. Impact of an electronic cigarette on smoking reduction and cessation in schizophrenic smokers: a prospective 12-month pilot study. Int J Environ Res Public Health. 2013;10(2):446-61. http://dx.doi.org/10.3390/ijerph10020446.

24. Caponnetto P, Polosa R, Russo C, Leotta C, Campagna D. Successful smoking cessation with electronic cigarettes in smokers with a documented history of recurring relapses: a case series. J Med Case Rep. 2011;5:585.

25. Caponnetto P, Polosa R, Auditore R, Russo C, Campagna D. Smoking cessation with e-cigarettes in smokers with a documented history of depression and recurring relapses. Int J Clin Med. 2011;2:281-4.

26. Schneiderhan M. A case report of patient-initiated e-cigarette use and resulting 5-months smoking cessation. J Pharm Pract. 2012;25(2):297.

27. Cummins SE, Zhu S-H, Tedeschi GJ, Gamst AC, Myers MG. Use of e-cigarettes by individuals with mental health conditions. Tob Control. 2014;23 suppl 3:iii48-53. doi:10.1136/tobaccocontrol-2013-051511.

28. Prochaska JJ, Grana RA. E-Cigarette Use among Smokers with Serious Mental Illness. PLoS One. 2014;9(11):e113013.

29. Bullen C, Williman J, Howe C, Laugesen M, McRobbie H, Parag V, et al. Study protocol for a randomised controlled trial of electronic cigarettes versus nicotine patch for smoking cessation. BMC Public Health. 2013;13:210. doi:10.1186/471-2458-13-210.

30. WHO Collaborating Centre for Drug Statistics Methodology. ATC structure and principles. 2011. [cited 2013 29/11/13]; Available from: http://www. webcitation.org/6LTKY7A7C

31. Heatherton T, Kozlowski L, Frecker R, Fagerstrom K. The fagerstrom test for nicotine dependence: a revision of the fagerstrom tolerance questionnaire. Br J Addict. 1991;86(9):1119-27.

32. Glover ED, Nilsson F, Westin A, Glover PN, Laflin MT, Persson B. Developmenta history of the Glover-Nilsson smoking behavioral questionnaire. Am J Health Behav. 2005;29(5):443-55. doi:10.5555/ajhb.2005.29.5.443.

33. DiFranza JR, Wellman RJ, Ursprung WW, Sabiston C. The autonomy over smoking scale. Psychol Addict Behav. 2009;23(4):656-65. doi:10.1037/a0017439.

34. Hajek P. Electronic cigarettes for smoking cessation. Lancet. 2013. http://dx.doi.org/10.1016/S0140-6736(13)61534-2.

35. NICE. National Institute for Health and Clinical Excellence (NICE). Tobacco: harm-reduction approaches to smoking. PH45. 2013 01-Dec-2014; Available from: https://www.nice.org.uk/guidance/ph45.

36. Wilson N, Weerasekera D, Collings S, Edwards R, Deen FS. Poorer mental health in many New Zealand smokers: national survey data from the ITC Project. N Z Med J. 2010;123(1326):129-32

\section{Submit your next manuscript to BioMed Central and take full advantage of:}

- Convenient online submission

- Thorough peer review

- No space constraints or color figure charges

- Immediate publication on acceptance

- Inclusion in PubMed, CAS, Scopus and Google Scholar

- Research which is freely available for redistribution 